\title{
The Effect of Internal Mammary Artery Grafts on Long-Term Clinical Outcomes After Coronary Bypass Surgery
}

\author{
Mark A Hlatky MD ${ }^{1}$, David Shilane $\mathrm{PhD}^{1}$, Derek B Boothroyd PhD ${ }^{1}$, \\ Eric Boersma $\mathrm{PhD}^{2}$, Maria M Brooks $\mathrm{PhD}^{3}$, Didier Carrié MD PhD ${ }^{4}$, \\ Tim C Clayton $\mathbf{M S c}^{5}$, Nicolas Danchin MD $^{6}$, Marcus Flather MBBS FRCP, \\ Christian W Hamm MD $^{8}$, Whady A Hueb MD $^{9}$, Jan Kahler MD $^{10}$, \\ Neuza Lopes MD ${ }^{9}$, Stuart J Pocock PhD ${ }^{5}$, Alfredo Rodriguez MD PhD ${ }^{11}$, \\ Patrick Serruys MD $^{2}$, Ulrich Sigwart MD $^{12}$, Rodney H Stables MD $^{13}$
}

From ${ }^{1}$ Stanford University School of Medicine, Stanford, CA; ${ }^{2}$ Erasmus University, Rotterdam, The Netherlands; ${ }^{3}$ University of Pittsburgh, Pittsburgh, PA; ${ }^{4}$ Rangueil Hospital, Toulouse, France; ${ }^{5}$ London School of Hygiene and Tropical Medicine, London, United Kingdom; ${ }^{6}$ Hôpital Georges Pompidou, Paris, France; ${ }^{7}$ Royal Brompton \& Harefield NHS Trust, London, United Kingdom; ${ }^{8}$ Kerckhoff Klinik, Bad Nauheim, Germany; ${ }^{9}$ Instituto do Coracäo, Säo Paulo, Brazil; ${ }^{10}$ Universitäres Herzzentrum, Hamburg, Germany;

${ }^{11}$ Sanatario Otamendi, Buenos Aires, Argentina; ${ }^{12}$ Université de Genevè, Geneva, Switzerland; ${ }^{13}$ Cardiothoracic Centre Liverpool, Liverpool, United Kingdom

\author{
Address for correspondence: \\ Mark A. Hlatky, MD \\ Stanford University School of Medicine \\ HRP Redwood Building, Room 150 \\ 259 Campus Drive \\ Stanford, CA 94305-5405 \\ Phone: (650) 723-6426 \\ FAX: (650) 725-6951 \\ E-Mail: hlatky@stanford.edu
}

Subject Codes: [36] - CV surgery, coronary artery disease [100]- Health policy and outcomes research 


\begin{abstract}
Background. Internal mammary artery (IMA) grafts have better patency than vein grafts, but their effects on long-term clinical outcomes after coronary bypass surgery have been evaluated in only a few studies.
\end{abstract}

Methods and Results. We analyzed clinical outcomes over a median follow-up of 5.9 years among 3,087 patients who received coronary bypass surgery as participants in one of eight clinical trials comparing surgery with angioplasty. We used two statistical methods (covariate adjustment and propensity score matching) to adjust for the non-randomized selection of IMA grafts. Both methods showed lower mortality associated with IMA grafting, with hazard ratios (confidence intervals) of 0.77 (0.62 to 0.97$)$ for covariate adjustment and 0.77 (0.57 to 1.05$)$ for propensity score matching. The composite endpoint of death or myocardial infarction was reduced to a similar extent, with hazard ratios of 0.83 (0.69 to 1.00$)$ for covariate adjustment to $0.78(0.61$ to 1.00$)$ for propensity score matching. There was a nonsignificant trend towards less angina at one year, with odds ratios of 0.81 ( 0.61 to $1.09)$ in the covariate adjusted model and $0.81(0.55$ to 1.19$)$ in the propensity score adjusted model.

Conclusion. Use of an IMA graft during coronary bypass surgery seems to improve long-term clinical outcomes.

Key Words: Coronary disease, revascularization 
The internal mammary artery (IMA) has better long-term patency than the saphenous vein when used as a conduit in coronary artery bypass graft surgery (CABG) (1-3). While it is widely believed that this higher patency rate leads to better long-term clinical outcomes, there are few data to support this assumption. Only one randomized trial has compared use of IMA grafts with saphenous vein grafts (4). In that trial, patients assigned to receive an IMA graft had fewer composite endpoints of cardiac death, myocardial infarction, repeat revascularization and cardiac hospitalization over 10 years ( 12 of 39 versus 21 of $41, p<0.05$ ), but did not differ significantly in any other endpoint. The results of this trial are not definitive because of its small size and because the outcome differences were driven mostly by cardiac hospitalizations rather than death or myocardial infarction. Observational, nonrandomized studies of between 743 and 5,931 patients who underwent CABG in the 1970s suggest that patients who received an IMA graft had improved long-term survival compared with patients who received only saphenous vein grafts (5-7). Patients selected to receive an IMA graft, however, differed in many clinical characteristics from patients selected to receive only vein grafts, and these differences may have introduced selection bias into the comparison of outcomes that can be difficult to control using statistical methods. Newer approaches to the analysis of observational data may help control for differences between patients selected for different treatments (8-11), although selection biases not captured by measured covariates may still exist (12). The purpose of this study was to apply both propensity score methods and covariate adjustment methods to compare the longterm outcomes of a more contemporary sample of patients who underwent CABG with or without an IMA graft. 


\section{Methods}

Investigators from ten randomized trials of $C A B G$ versus percutaneous coronary intervention for multivessel coronary disease pooled individual patient data as part of a collaborative analysis of long-term treatment outcomes, as described previously (13). The present study is based on data from the eight trials that provided individual patient data on the use of IMA grafts among patients assigned to CABG (14-21). Use of IMA grafting in these trials was based on surgeon preference, and was not randomized.

We used multivariable logistic regression to compare baseline clinical characteristics of patients who received an IMA graft with those who did not. The results of this model were used to create a propensity score that estimated the probability of each patient receiving an IMA graft. For the propensity score matched analyses, we identified pairs of patients, one of whom received an IMA graft and one of whom did not, using an algorithm (22) that first paired the patients with the closest propensity scores, then paired the patients with the next closest propensity scores, etc., and stopped matching when propensity scores differed by more than 0.01 . We required that each pair of patients be drawn from the same clinical trial, and be matched on the presence or absence of diabetes.

We assessed time-to-event for three major clinical outcomes: death; death or myocardial infarction; and death or myocardial infarction or repeat revascularization. These endpoints were defined by each trial using specific protocol definitions (1421).

We used Cox proportional hazards models to analyze time-to-event outcomes, and logistic regression to analyze angina at one year. We performed two sets of analyses for each outcome. In the first set of analyses, we compared 
outcomes of patients with and without an IMA graft among all patients, adjusting for patient baseline clinical characteristics (Table 1), and stratifying by trial. In the second set of analyses, we compared outcomes of patients with and without an IMA graft in the subset of patients who were matched on propensity score, adjusting for baseline clinical characteristics, and stratifying by trial. All statistical analyses were performed with $\mathrm{R}$ Version 2.8.1.

\section{Results}

Data on IMA use were available for 3,087 patients who received CABG in one of eight clinical trials. The 2,573 patients (83\%) who received an IMA graft were significantly less likely to be female, to have heart failure or a prior myocardial infarction, and significantly more likely to have proximal disease of the left anterior descending coronary artery or triple-vessel disease (Table 1). The use of IMA grafts also varied significantly by trial, ranging from $39 \%$ in GABI (17) to $96 \%$ in ERACI-II (16). The multivariable propensity score showed that the strongest predictor of whether or not a patient received an IMA graft was the trial in which the patient was enrolled, followed by heart failure, presence of disease in the proximal left anterior descending artery, female gender, and the presence of three-vessel disease (Table 2). We were able to match on propensity score 437 of the 514 (85\%) patients who did not receive an IMA graft with 437 patients from the same trial who did receive an IMA graft. As expected, the matched groups had very similar baseline characteristics (Table 1).

Among all patients receiving CABG, the unadjusted Kaplan-Meier mortality rate at five years was $2.6 \%$ lower among patients who received an IMA graft than patients who received vein grafts only, and at ten years the mortality rate was $1.9 \%$ 
lower in the IMA group (Table 3). In a Cox model that was stratified by study and adjusted for all of the baseline characteristics in Table 1, use of an IMA graft was associated with a significantly lower risk of death, with a hazard ratio of 0.77 (confidence interval 0.62 to $0.97, p=0.02$ ). Use of an IMA graft was also associated with a significantly reduced chance of the composite endpoint of death or myocardial infarction and the composite endpoint of death or myocardial infarction or repeat revascularization (Tables 3 and 4). Angina at one year was also less frequent among patients who received an IMA graft, but not significantly so (Tables 3 and 4).

Among 437 pairs of patients matched on propensity score, study and diabetes, five-year mortality was $2.3 \%$ lower among patients who received an IMA graft than among patients who did not, and at ten years mortality was $2.5 \%$ lower in the IMA group (Figure 1, Table 3). In a Cox model stratified by study, use of an IMA graft was associated with a lower risk of death, with a hazard ratio of 0.78 (confidence limits 0.57 to $1.05, p=0.10$ ). The hazard ratio was essentially unchanged after additional adjustment for baseline characteristics ( 0.77 , confidence limits 0.57 to $1.05, \mathrm{p}=0.10$ ). There was a significantly lower incidence of the composite endpoint of death or MI (Figure 2, Table 3) and of the composite endpoint of death, MI, or repeat revascularization (Figure 3, Table 3). Angina at one year was less frequent among patients who received an IMA graft, but not significantly so (Tables 3 and 4).

\section{Discussion}

Our analysis confirms that patients who receive IMA grafts differ significantly from patients who receive only vein grafts in a number of prognostically important clinical characteristics (Table 1), including sex, a history of MI and of heart failure, and extent of coronary disease (Table 2). After adjusting for these and other differences using several different statistical methods, we found that use of an IMA 
graft was associated with $23 \%$ lower risk of death over a 5.9 year median follow-up (Table 4). These results are generally consistent with the $38 \%$ risk reduction over 10 years reported by Loop and associates (5), the $27 \%$ risk reduction over 15 years reported by Cameron and coworkers (6), and the 32\% risk reduction over 20 years reported by Cameron and associates (7). The long-term risk reductions associated with use of IMA grafts are not as striking as the $56 \%$ to $74 \%$ reductions in procedural mortality reported by large clinical databases (23-26), but comparisons of 30-day mortality after CABG may be more susceptible to selection bias.

In addition to an association with lower mortality, IMA use in our study was also associated with lower rates of myocardial infarction, repeat revascularization, and angina (Tables 3 and 4). The consistency of the effect of IMA use on these additional endpoints is reassuring. Our results, in conjunction with earlier studies (5, 6) suggest that the better long-term patency of the IMA graft seems to translate into improved long-term clinical outcomes.

IMA grafting has not been tested in a large, long-term clinical trial, so nonrandomized observational comparisons are the only source of information on the comparative effectiveness of IMA grafts and vein grafts. Patients selected for alternative treatments differ in a number of ways, however, so multivariable statistical methods have been used in an attempt to adjust for clinically important differences between patient groups. A variety of methods has been used (27), including direct adjustment for confounding factors in a multivariable model, propensity score adjustment and matching $(8,9)$, and instrumental variables methods $(28,29)$, among others. Typically, investigators choose just one of these methods to analyze their data, but recent studies have shown that the results of alternative models applied to the same dataset may well differ $(30,31)$. We applied 
several approaches to the analysis of these data to evaluate whether the results would be affected by the choice of a statistical model. The magnitude of the effect of IMA on several outcome measures was quite similar whether we used direct adjustment for baseline covariates or propensity score matching, although the confidence limits were wider when sample size was reduced by matching. These alternative approaches may have yielded similar results in the present study because some adverse prognostic factors had a higher prevalence in the IMA group (three-vessel disease, proximal left anterior descending disease), while other adverse prognostic factors had a lower prevalence in the IMA group (abnormal left ventricular function, prior myocardial infarction). Consequently, prognosis at study entry may have been relatively similar in the IMA and vein graft groups due to offsetting imbalances in different baseline characteristics. Furthermore, all patients in this analysis had been selected to participate in a clinical trial, and may have had a narrower range of clinical characteristics than unselected patients undergoing CABG. The similarity in the results of alternative statistical approaches in our study should not be interpreted as showing these methods would yield equivalent results in other observational treatment comparisons.

This study has a number of limitations. While the data were drawn from clinical trials of CABG and coronary angioplasty, the use of IMA grafting was not randomized and varied considerably among the participating trials, and according to patient characteristics. We had only relatively simple clinical data available on all patients, so were unable to adjust for characteristics such as extent of atherosclerosis, and residual selection bias due to unmeasured confounders may be present (12). Finally, all patients underwent CABG between 1988 and 2000, and 
may not completely reflect the results of contemporary CABG, although all were treated in centers with excellent cardiac surgical programs.

In conclusion, these data provide additional evidence that use of an IMA graft appears to improve long-term outcomes after CABG, and suggest that IMA use may be a reasonable process measure of the quality of care for $\operatorname{CABG}(32,33)$. 


\section{References}

1. Grondin CM, Campeau L, Lespérance J, Enjalbert M, Bourassa MG. Comparison of late changes in internal mammary artery and saphenous vein grafts in two consecutive series of patients 10 years after operation. Circulation 1984;70:1208-1212. 2. Goldman S, Zadina K, Moritz T, Ovitt T, Sethi G, Copeland JG, Thottapurathu L, Krasnicka B, Ellis N, Anderson RJ, Henderson W. Long-term patency of saphenous vein and left internal mammary artery grafts after coronary artery bypass surgery. Results from a Department of Veterans Affairs Cooperative Study. J Am Coll Cardiol 2004;44:2149-2156.

3. Sabik JF, Lytle BW, Blackstone EH, Houghtaling PL, Cosgrove DM. Comparison of saphenous vein and internal thoracic artery graft patency by coronary system. Ann Thorac Surg 2005;79:544-551.

4. Zeff RH, Kongtahworn C, lannone LA, Gordon DF, Brown TM, Phillips SJ, Skinner JR, Spector M. Internal mammary artery versus saphenous vein graft to the left anterior descending coronary artery: Prospective randomized study with 10-year followup. Ann Thorac Surg 1988;45:533-536.

5. Loop FD, Lytle BW, Cosgrove DM, Stewart RW, Goormastic M, Williams GW, Golding LAR, Gill CC, Taylor PC, Sheldon WC, Proudfit WL. Influence of the internalmammary-artery graft on 10-year survival and other cardiac events. N Engl J Med $1986 ; 314: 1-6$

6. Cameron A, Davis KB, Green G, Schaff HV. Coronary bypass surgery with internal thoracic-artery grafts-effects on survival over a 15-year period. N Engl J Med 1996;334:216-219.

7. Cameron AAC, Green GE, Brogno DA, Thornton J. Internal thoracic artery grafts: 20-year clinical follow-up. J Am Coll Cardiol 1995;25:188-192. 
8. Rubin DB. The design versus the analysis of observational studies for causal effects: Parallels with the design of randomized trials. Stat Med 2007;26:20-36.

9. D'Agostino RB. Propensity scores in cardiovascular research. Circulation 2007;115:2340-2343.

10. Normand SLT. Some old and some new statistical tools for outcomes research. Circulation 2008;118:872-884.

11. Austin PC. Report card on propensity-score matching in the cardiology literature from 2004 to 2006. A systematic review. Circ Cardiovasc Qual Outcomes 2008;1:62-67. 12. Pocock SJ, Elbourne DR. Randomized trials or observational tribulations? N Engl J Med 2000;342:1907-1909.

13. Hlatky MA, Boothroyd DB, Bravata DM, Boersma E, Booth J, Brooks MM, Carrié D, Clayton TC, Danchin N, Flather M, Hamm CW, Hueb WA, Kähler J, Kelsey SF, King SB, Kosinski AS, Lopes N, McDonald KM, Rodriguez A, Serruys P, Sigwart U, Stables $\mathrm{RH}$, Owens DK, Pocock SJ. Coronary artery bypass surgery compared with percutaneous coronary interventions for multivessel disease: A collaborative analysis of individual patient data from ten randomized trials. Lancet 2009;373:1190-1197.

14. Serruys PW, Unger F, Sousa JE, Jatene A, Bonnier HJRM, Schönberger JPAM, Buller N, Bonser R, van den Brand MJB, van Herwerden LA, Morel MAM, van Hout BA. Comparison of coronary-artery bypass surgery and stenting for the treatment of multivessel disease. N Engl J Med 2001;344:1117-1124.

15. The BARI Investigators. The final 10-year follow-up results from the BARI randomized trial. J Am Coll Cardiol 2007;49:1600-1606.

16. Rodriguez AE, Baldi J, Pereira CF, Navia J, Alemparte MR, Delacasa A, Vigo F, Vogel D, O'Neill W, Palacios IF. Five-year follow-up of the Argentine randomized trial of coronary angioplasty with stenting versus coronary bypass surgery in patients with multiple vessel disease (ERACI II) J Am Coll Cardiol 2005;46:582-588. 
17. Hamm CW, Reimers J, Ischinger T, Rupprecht HJ, Berger J, Bleifeld W, German Angioplasty Bypass Surgery Investigation (GABI). A randomized study of coronary angioplasty compared with bypass surgery in patients with symptomatic multivessel coronary disease. N Engl J Med 1994;331:1037-1043.

18. Hueb W, Lopes NH, Gersh BJ, Soares P, Machado LAC, Jatene FB, Oliveira SA, Ramires JAF. Five-year follow-up of the Medicine, Angioplasty, or Surgery Study (MASS II). A randomized controlled clinical trial of 3 therapeutic strategies for multivessel coronary artery disease. Circulation 2007;115:1082-1089.

19. RITA Trial Participants. Coronary angioplasty versus coronary artery bypas surgery: The Randomised Inervention Treatment of Angina (RITA) trial. Lancet 1993;341:573-580.

20. Booth J, Clayton T, Pepper J, Nugara F, Flather M, Sigwart U, Stables RH. Randomized, controlled trial of coronary artery bypass surgery versus percutaneous coronary intervention in patients with multivessel coronary artery disease. Six-year follow-up from the Stent or Surgery Trial (SoS). Circulation 2008;118:381-388.

21. Carrié D, Elbaz M, Puel J, Fourcade J, Karouny E, Fournial G, Galinier M. Fiveyear outcome after coronary angioplasty versus bypass surgery in multivessel coronary artery disease. Results from the French Monocentric Study. Circulation 1997;96[suppl II]:II-1-II-6.

22. Rosenbaum PR. Optimal matching for observational studies. J Am Stat Assoc 1989;84:1024-1032.

23. Karthik S, Srinivasan AK, Grayson AD, Jackson M, Mediratta NK. Left internal mammary artery to the left anterior descending artery: Effect on morbidity and mortality and reasons for nonusage. Ann Thorac Surg 2004;78:142-148. 
24. Dabal RJ, Goss JR, Maynard C, Aldea GS. The effect of left internal mammary artery utilization on short-term outcomes after coronary revascularization. Ann Thorac Surg 2003;76:464-470.

25. Leavitt BJ, O'Connor GT, Olmstead EM, Morton JR, Maloney CT, Dacey LJ, Hernandez F, Lahey SJ. Use of the internal mammary artery graft and in-hospital mortality and other adverse outcomes associated with coronary artery bypass surgery. Circulation 2001;103:507-512.

26. Edwards FH, Clark RE, Schwartz M. Impact of internal mammary artery conduits on operative mortality in coronary revascularization. Ann Thorac Surg 1994;57:27-32.

27. Malenka DJ, Leavitt BJ, Hearne MJ, Robb JF, Baribeau YR, Ryan TJ, Helm RE, Kellett MA, Dauerman HL, Dacey LJ, Silver MT, VerLee PN, Weldner PW, Hettleman BD, Olmstead EM, Piper WD, O'Connor GT. Comparing long-term survival of patients with multivessel coronary disease after CABG or PCI. Analysis of BARI-like patients in Northern New England. Circulation 2005;112[suppl I]:I-371-I-376.

28. McClellan M, McNeil BJ, Newhouse JP. Does more intensive treatment of acute myocardial infarction in the elderly reduce mortality? Analysis using instrumental variables. JAMA 1994;272:859-866.

29. Newhouse JP, McClellan M. Econometrics in outcomes research: The use of instrumental variables. Annu Rev Public Health 1998;19:17-34.

30. Stukel TA, Fisher ES, Wennberg DE, Alter DA, Gottlieb DJ, Vermeulen MJ.

Analysis of observational studies in the presence of treatment selection bias: Effects of invasive cardiac management on AMI survival using propensity score and instrumental variable methods. JAMA 2007;297:278-285.

31. Suaya JA, Stason WB, Ades PA, Normand SLT, Shepard DS. Cardiac rehabilitation and survival in older coronary patients. J Am Coll Cardiol 2009;54:25-33. 
32. Karthik S, Fabri BM. Left internal mammary artery usage in coronary artery bypass grafting: A measure of quality control. Ann R Coll Surg Engl 2006;88:367-369. 33. Tabata M, Grab JD, Khalpey Z, Edwards FH, O'Brien SM, Cohn LH, Bolman M. Prevalence and variability of internal mammary artery graft use in contemporary multivessel coronary artery bypass graft surgery. Analysis of the Society of Thoracic Surgeons National Cardiac Database. Circulation 2009;120:935-940. 
Table. 1. Baseline Characteristics by Use of Internal Mammary Artery

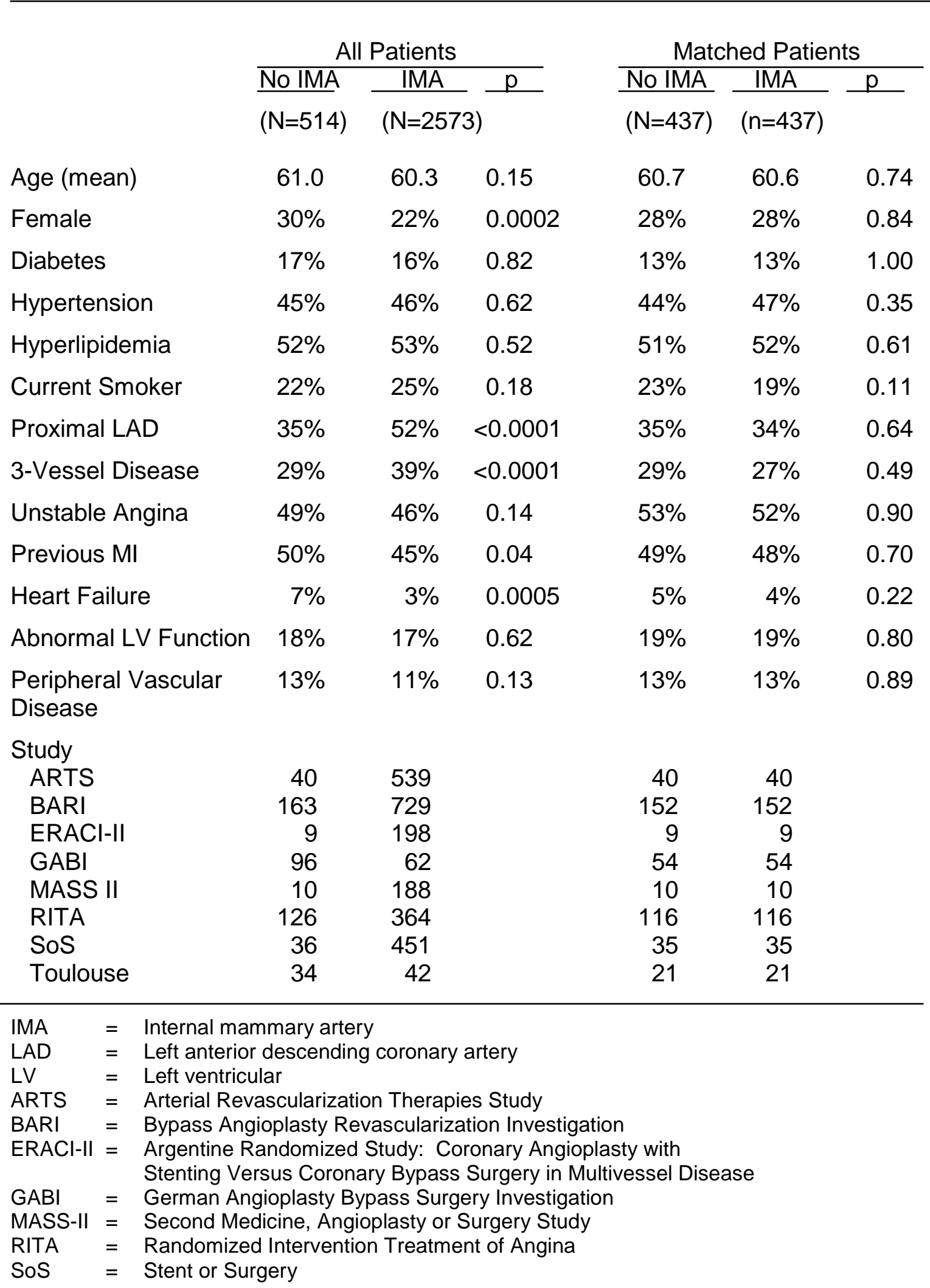


Table 2. Propensity Score for Receiving an Internal Mammary Artery Graft

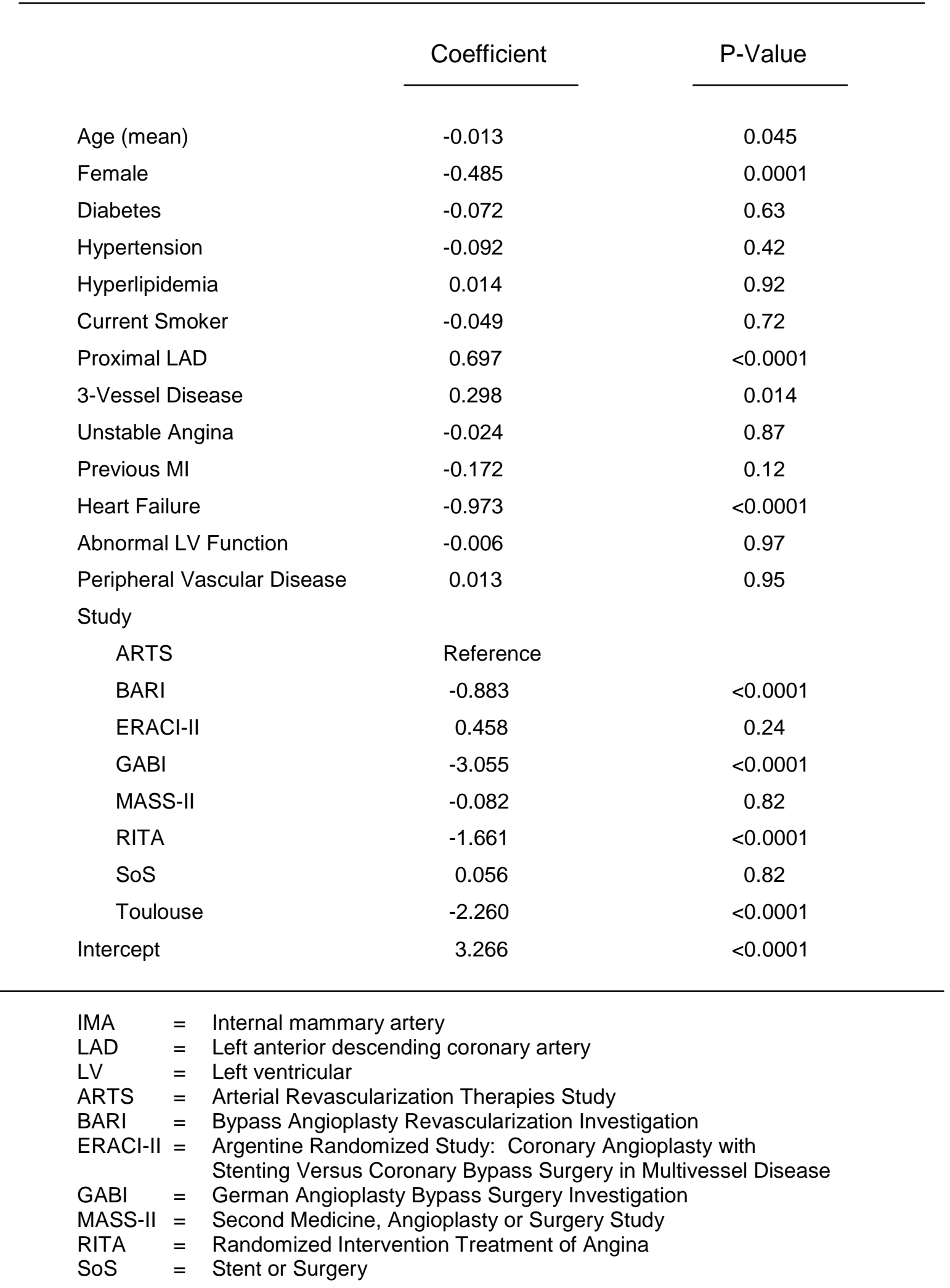


Table 3. Incidence of Clinical Outcomes in Follow-Up by Use of the Internal Mammary Artery, Based on Pooled, Unadjusted Data

\begin{tabular}{|c|c|c|c|c|}
\hline \multirow[t]{3}{*}{ Outcome } & \multicolumn{2}{|c|}{ All Patients } & \multicolumn{2}{|c|}{ Matched Patients } \\
\hline & No IMA & IMA & No IMA & IMA \\
\hline & $(\mathrm{N}=514)$ & $(\mathrm{N}=2573)$ & $(\mathrm{N}=437)$ & $(n=437)$ \\
\hline \multicolumn{5}{|l|}{ Death (\%) } \\
\hline 5 years* & 10.4 & 7.8 & 10.4 & 8.1 \\
\hline 10 years $^{*}$ & 22.5 & 20.6 & 21.7 & 19.2 \\
\hline \multicolumn{5}{|l|}{ Death or MI (\%) } \\
\hline 5 years $^{*}$ & 19.2 & 15.4 & 19.1 & 13.8 \\
\hline 10 years* & 33.3 & 30.4 & 32.2 & 27.6 \\
\hline \multicolumn{5}{|c|}{$\begin{array}{l}\text { Death, Ml or Repeat } \\
\text { Revascularization (\%) H }\end{array}$} \\
\hline 5 years $^{*}$ & 20.1 & 14.3 & 19.8 & 16.9 \\
\hline 10 years* & 40.8 & 37.4 & 40.2 & 36.6 \\
\hline Angina at 1 year (\%) & 17.8 & 12.8 & 17.8 & 15.4 \\
\hline
\end{tabular}

* Kaplan-Meier estimates

H Data omits the Toulouse Study

IMA = Internal mammary artery

$\mathrm{MI}=$ Myocardial infarction 
Table 4. Comparative Outcomes: Hazard Ratio for IMA vs. No IMA in Cox Models Stratified by Study and Adjusted for Baseline Clinical Characteristics

\begin{tabular}{|c|c|c|c|c|}
\hline & \multicolumn{2}{|l|}{$\begin{array}{l}\text { All Patients } \\
(\mathrm{N}=3087)\end{array}$} & \multicolumn{2}{|l|}{$\begin{array}{l}\text { Matched Patients } \\
\quad(\mathrm{N}=874)\end{array}$} \\
\hline & Hazard Ratio (Cl) & $P$ & Hazard Ratio $(\mathrm{Cl})$ & $P$ \\
\hline Death & $0.77(0.62-0.97)$ & 0.02 & $0.77(0.57-1.05)$ & 0.10 \\
\hline Death/Ml & $0.83(0.69-1.00)$ & 0.05 & $0.78(0.61-1.00)$ & 0.05 \\
\hline $\begin{array}{l}\text { Death/Ml/Repeat } \\
\text { Procedure }\end{array}$ & $0.82(0.69-0.98)$ & 0.03 & $0.85(0.67-1.08)$ & 0.18 \\
\hline Angina* (One Year) & $0.81(0.61-1.09)$ & 0.16 & $0.81(0.55-1.19)$ & 0.28 \\
\hline
\end{tabular}

* Logistic regression model used to assess angina at one year. The data shown are odds ratios (95\% confidence interval).

$\mathrm{Cl}=$ Confidence interval

$\mathrm{MI}=$ Myocardial infarction 


\section{Figure Legends}

Figure 1. Cumulative rate of mortality (vertical axis) over ten years of follow-up (horizontal axis) in patients matched on propensity score. The outcome of patients who received an internal mammary artery (IMA) graft is indicated by the solid line and the survival of patients who received only vein grafts is indicated in the dashed line. The number of patients followed alive at each annual interval in each group is indicated below the horizontal axis.

Figure 2. Cumulative rate of death or myocardial infarction over ten years of follow-up. Format as in Figure 1.

Figure 3. Cumulative rate of death, myocardial infarction or repeat revascularization over ten years of follow-up. Long-term data on repeat procedures were not available from the Toulouse study. Format as in Figure 1. 


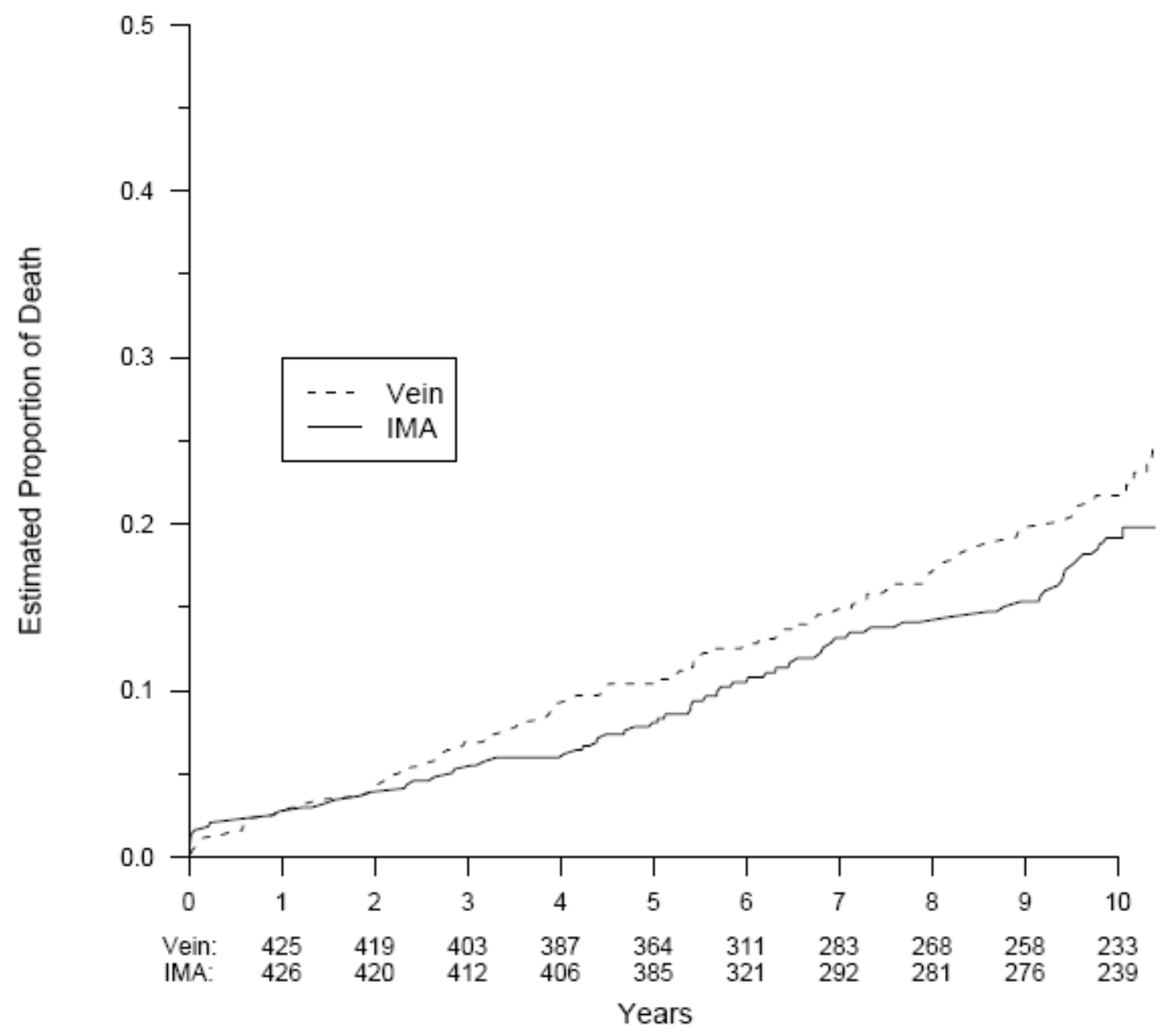




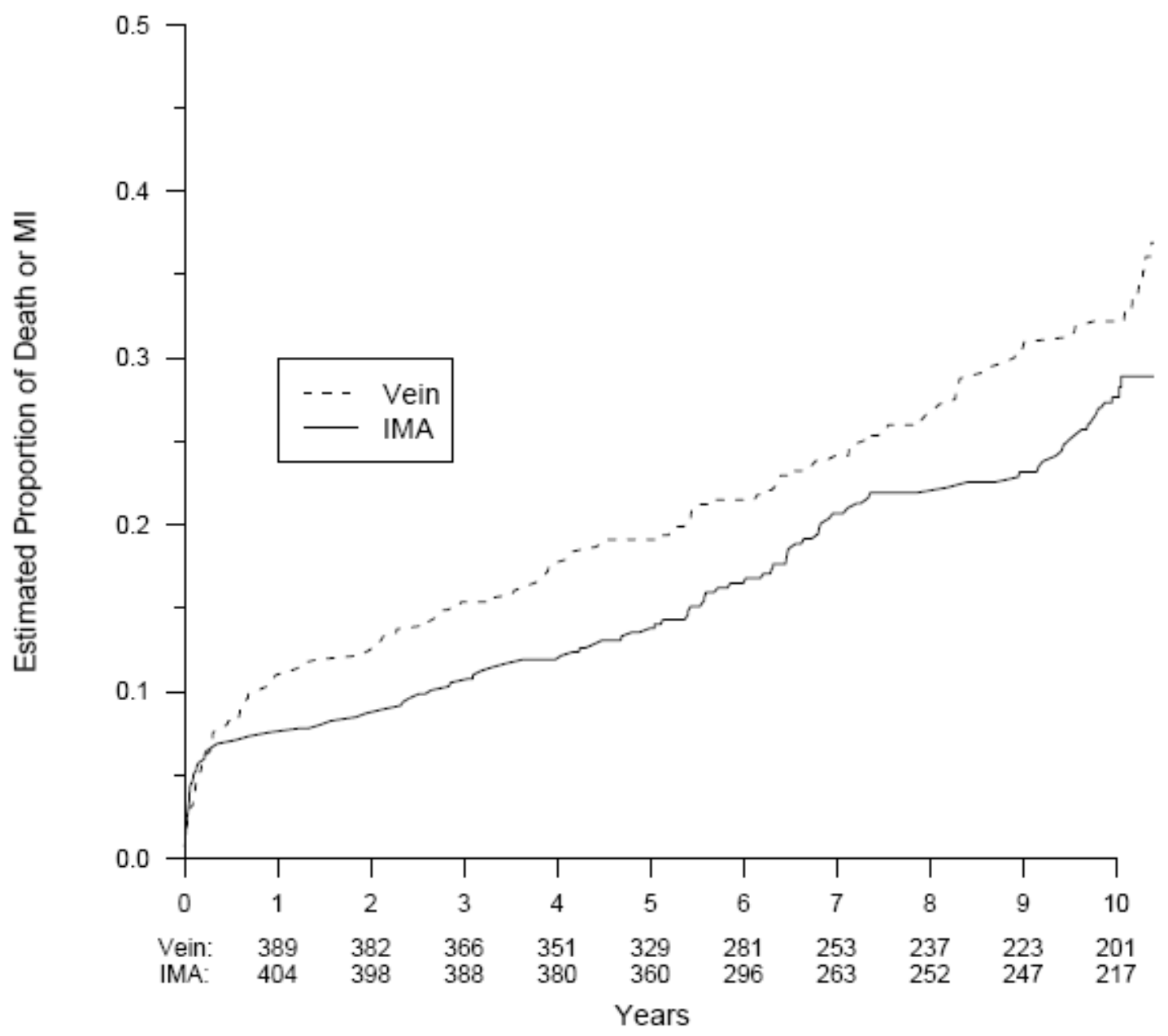




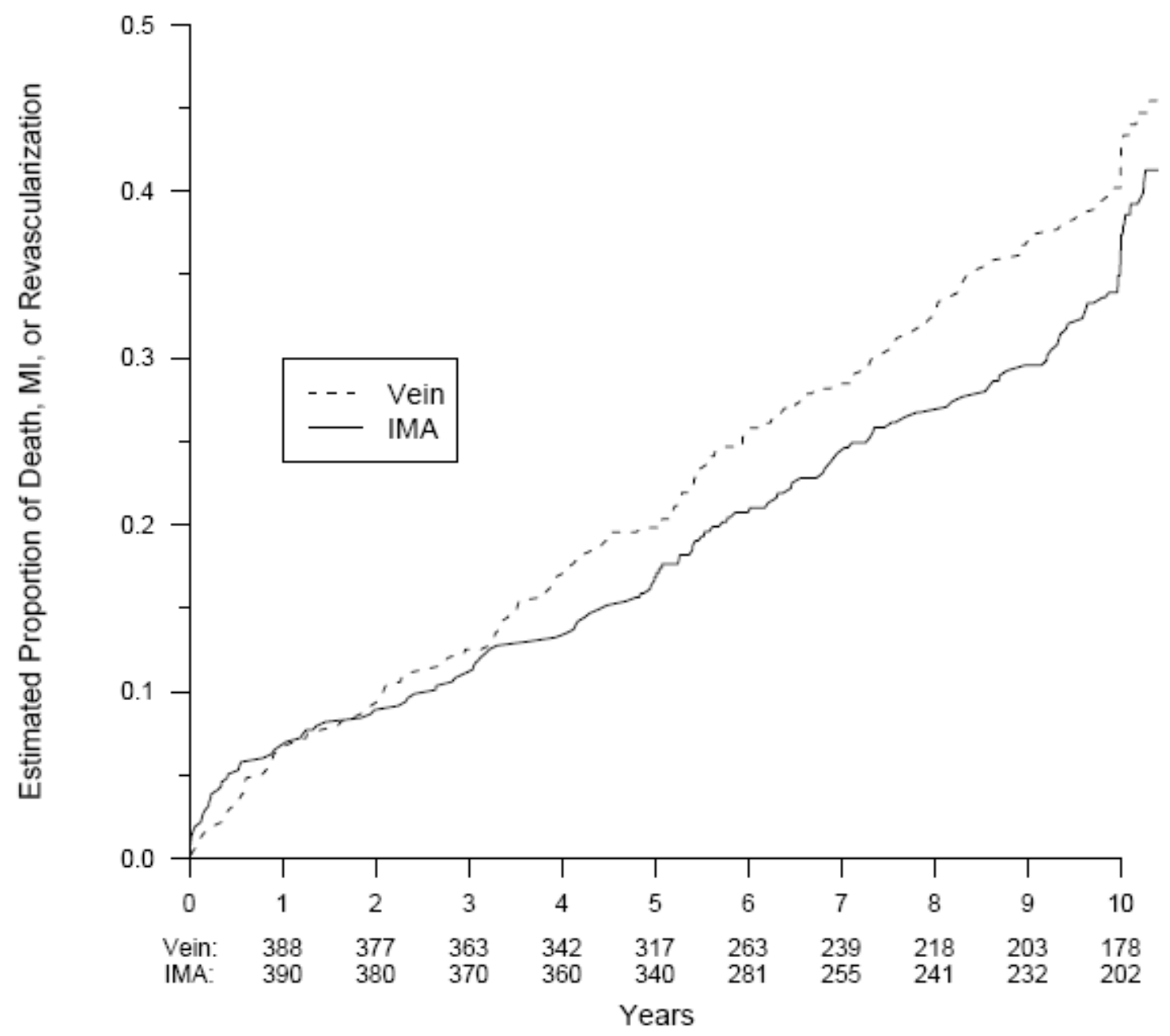

